\title{
A prática de análise linguística no livro didático: uma perspectiva em construção
}

The practice of linguistic analysis in textbook: a perspective in construction

\author{
Francieli Heineck* \\ Francieli Matzenbacher Pinton**
}

RESUMO: Levando em consideração que o livro didático é, formalmente, um dos materiais estruturadores dos conhecimentos transmitidos nas escolas, este artigo tem como objetivo analisar de que forma o ensino de gramática se efetiva nos livros didáticos, em específico no livro do $6^{\circ}$ ano da coleção Português: linguagens (2012). O corpus de análise compreende nove seções intituladas "língua em foco". Nestas seções são abordadas as classes de palavras, dentre elas o substantivo, o adjetivo, o artigo, o numeral, o pronome e o verbo. As seções foram analisadas com foco nos contrastes entre ensino de gramática normativa e prática de análise linguística (MENDONÇA, 2006). Os resultados sinalizam que, embora o ensino reflexivo da língua seja apontado como um dos pontos fortes do livro, segundo o Guia de livros didáticos de Língua Portuguesa, esse ensino, em certa medida, não se efetiva nas seções analisadas, já que há a prevalência da prescrição em detrimento da reflexão.

PALAVRAS-CHAVE: Livro didático. Ensino. Análise linguística.
ABSTRACT: Considering that the textbook is formally one of the essential materials of the knowledge transmitted in schools, this article aims to analyze how grammar teaching is effective in textbooks, in particular in the book of the 6th year of the collection Português: linguagens (2012). The corpus comprises nine sections entitled "lingua em foco". In these sections, word classes are addressed, among them, nouns, adjectives, articles, numerals, pronouns and verbs. The sections were analyzed with a focus on contrasts between normative grammar teaching and linguistic analysis practice (MENDONÇA, 2006). The results indicate that although the reflective language teaching is pointed as one of the strengths of the textbook according to the Guia de livros didáticos de Língua Portuguesa, this teaching to some extent is not effective in the analyzed sections, since there is a prevalence of prescription to the detriment of reflection.

KEYWORDS: Textbook. Teaching. Linguistic analysis.

\section{Introdução}

Levando em consideração que o livro didático é, formalmente, um dos materiais estruturadores dos conhecimentos transmitidos nas escolas, muitas pesquisas têm sido realizadas a seu respeito. Elas se intensificaram, nas últimas décadas, com as discussões a respeito do papel que este livro assume no processo de ensino-aprendizagem.

\footnotetext{
* Graduanda do Curso de Licenciatura em Letras: Português e Espanhol da Universidade Federal da Fronteira Sul (UFFS) - Campus Cerro Largo.

** Doutora em Letras; Professora Adjunto I na Universidade Federal da Fronteira Sul (UFFS) - Campus Cerro Largo.
} 
Nas aulas de Língua Portuguesa, em específico, essas discussões giram em torno da dicotomia entre um ensino tradicional e um ensino que privilegie a análise linguística. Nesse contexto, os autores de livros didáticos estão, cada vez mais, propondo-se a (re)pensá-los de maneira diferenciada, na qual haja reflexão recorrente, organizada e voltada para a produção de sentidos. Mas muitas dessas propostas, ainda que sejam bem intencionadas, não conseguem se desprender consideravelmente de uma perspectiva normativa e prescritiva.

Diante dessa realidade, pretendemos analisar a proposta de ensino de gramática presente no livro do $6^{\circ}$ ano da coleção Português: linguagens (CEREJA; MAGALHÃES, 2012), abordando contrastes entre ensino de gramática normativa e prática de análise linguística. Para tanto, dividimos o presente trabalho em diferentes momentos: primeiramente, apresentamos um breve histórico da disciplina Língua Portuguesa no Brasil e uma revisão das principais concepções de gramática e de ensino subjacentes à disciplina; em segundo momento, resgatamos a história e o papel do livro didático no Ensino Fundamental e, por fim, expomos nossa metodologia de análise e os resultados a que chegamos com este trabalho.

\section{Breve histórico da disciplina de língua portuguesa no Brasil}

Hoje todos estão familiarizados com a presença da disciplina Língua Portuguesa na escola. Mas são poucos os que sabem que essa disciplina passou a fazer parte do currículo escolar muito tardiamente. Segundo Rojo (2008), ela é introduzida nos currículos oficiais para o ensino secundário apenas em 1838 (nos anos iniciais do Colégio Pedro II), convivendo, timidamente, com o estudo do trivium $^{1}$ (gramática, retórica e lógica ou filosofia). E é apenas no final do Império que as disciplinas retórica, poética e gramática se fundiram numa só disciplina, que passou a se chamar Português (permanecendo embutidas nela as disciplinas anteriores).

Para Soares (2004), é partir de 1950 que se inicia um processo de modificações no conteúdo da disciplina, decorrente da inserção de filhos de trabalhadores nas instituições de ensino. Nesse período, texto e gramática passam a compor um só livro, ainda que separados: metade do livro se destinava à gramática e a outra metade, ao texto. Somente em 1960 ocorre uma fusão entre texto e gramática, ambos sendo organizados em unidades, mas com prioridade para a gramática.

\footnotetext{
${ }^{1}$ Rojo (2008, p. 79) explica que as sete disciplinas ou sete artes liberais eram divididas, nas universidades da Idade Média, em trivium, que reunia as disciplinas que se ocupavam do discurso e da palavra, e em quadrivium, que reunia as disciplinas referentes ao estudo da natureza.
} 
A autora aponta ainda que, a partir da Lei de Diretrizes e Bases da Educação (Lei $n^{\circ}$ 5692/71), ocorreram mudanças de caráter político e ideológico em relação à disciplina Português. Tais mudanças se refletem tanto na denominação da disciplina e em seus objetivos quanto na concepção de língua. Segundo Soares:

Uma recuperação da história da instituição da língua portuguesa em disciplina curricular permite encontrar as razões por que essa instituição se tenha feito privilegiando em cada momento, determinados aspectos do conhecimento sobre a língua: inicialmente, as disciplinas gramática, retórica, poética, posteriormente, a disciplina abrangente que se denominou português que, por sua vez, em certo momento, passou a denominar-se comunicação e expressão e comunicação em língua portuguesa, para em seguida voltar à denominação português; e permite também encontrar as razões por que os conteúdos atribuídos a essas disciplinas tenham sido ora uns, ora outros - de início, a arte de falar bem, a arte da elocução, e o estudo da poesia; depois os estudos estilísticos .... a gramática, sempre... - e por que as concepções de língua que informaram esses conteúdos tenham sido diferentes, ao longo do tempo - a língua como sistema, a língua como comunicação, a língua como discurso... (SOARES, 2004, p. 174-175)

Da mesma forma como foram privilegiados certos aspectos do conhecimento na constituição da disciplina Língua Portuguesa, aínda hoje o ensino depende de fatores que são privilegiados ou não pelos professores, dependendo de suas concepções e crenças. Exemplo disso são as concepções de gramática e de ensino, que serão expostas a seguir.

\section{Concepção de gramática e de ensino}

Martelotta (2009), ao se referir à gramática como modelo teórico criado pelos cientistas para explicar o funcionamento da língua, elenca cinco concepções de gramática: gramática tradicional, gramática histórico-comparativa, gramática estrutural, gramática gerativa e gramática cognítivo-funcional.

A gramática tradicional, também chamada de gramática normativa ou gramática escolar, é apontada pelo autor como aquela que, tendo origem com os filósofos da Grécia antiga, prevalece até hoje nas escolas. Estando fundamentada em padrões de correção de caráter impositivo e normativo, essa tradição não aceita o processo natural de variação da língua em decorrência de seu uso social. Desse modo, abrangeria somente uma parte da língua, não podendo explicá-la em sua totalidade. (MARTELOTTA, 2009, p. 45-46)

Já a gramática histórico-comparativa tem como proposta comparar elementos gramaticais de línguas de mesma origem com o objetivo de detectar a estrutura da língua 
original. Seus critérios são estritamente linguísticos e ressaltam a mutabilidade das línguas, propondo uma abordagem de caráter social e cultural. O autor sinaliza algumas limitações dessa concepção, como, por exemplo, centrar as mudanças linguísticas no indivíduo, não explicitando como o contexto de comunicação poderia interferir nessas mudanças. (MARTELOTTA, 2009, p. 47-53)

A gramática estrutural, por sua vez, desenvolveu-se com as ideias de Saussure e se caracteriza por "descrever a estrutura gramatical das línguas, vendo-as como um sistema autônomo, cujas partes se organizam em uma rede de relações de acordo com leis internas, ou seja, inerentes ao próprio sistema" (MARTELOTTA, 2009, p. 53). Assim, a linguagem é isolada dos indivíduos que a utilizam, ocasionando a exclusão de fenômenos sociointerativos.

A gramática gerativa surge das contribuições de Chomsky e se baseia, principalmente, nos princípios do inatismo (estrutura inata constituída de concepções universais) e da modularidade da mente (mente constituída por partes, sendo que cada parte responde pela estrutura e pelo desenvolvimento de determinada atividade cognitiva). Para Martelotta, essa concepção de gramática, assim como a anterior, deixa de lado os aspectos sociointerativos associados à linguagem, ou seja, é indiferente aos interesses do sujeito e às características do ambiente em que se situa. (MARTELOTTA,2009, p.58-62)

A gramática cognitivo-funcional apresenta uma concepção teórico-metodológica de escolas que reúnem pontos em comum, como a linguística sociocognitiva, a linguística textual, a sociolinguística e o funcionalismo. A gramática cognitivo-funcional, assim como a estrutural e a gerativa, também analisa a estrutura gramatical, mas o faz de maneira distinta, pois leva em consideração o propósito do evento de fala, seus participantes e seu contexto discursivo. Assim, dentro dessa concepção, a gramática não pode ser vista como independente do uso da língua, uma vez que se adapta às situações de interação. (MARTELOTTA, 2009, p. 62-63)

Já Travaglia (2009), diferentemente de Martelotta, aponta três concepções de gramática, tradicionalmente chamadas de normativa, descritiva e internalizada.

Por gramática normativa o autor entende que é a gramática “concebida como um manual com regras de bom uso da língua a serem seguidas por aqueles que querem se expressar adequadamente" (TRAVAGLIA, 2009, p. 24). Nesse sentido, a variedade chamada padrão ou culta seria a única possível na língua e todas as outras formas de uso seriam consideradas desvios ou erros. 
A gramática descritiva é assim chamada porque "faz, na verdade, uma descrição da estrutura e funcionamento da língua, de sua forma e função” (TRAVAGLIA, 2009, p. 27). Assim, ela representa um conjunto de regras utilizadas na construção real de enunciados, de modo a separar o que é gramatical do que não é. De acordo com o autor, são representantes dessa concepção as gramáticas feitas com base nas teorias estruturalista e gerativatransformacional, que propõem a homogeneidade do sistema linguístico ao abstrair a língua de seu contexto e trabalhar com um sistema formal abstrato.

A gramática internalizada, por fim, é percebida como “o conjunto das regras que o falante de fato aprendeu e das quais lança mão ao falar" (TRAVAGLIA, 2009, p. 28). Nesse sentido, saber gramática não depende, necessariamente, da escolarização, mas sim da ativação e da construção progressiva de hipóteses para o funcionamento da língua.

Quando pensamos em concepções de gramática, não podemos desconsiderar as concepções de ensino subjacentes a elas. De acordo com Travaglia (2009), o professor, ao ensinar uma língua, pode realizar três tipos de ensino: o prescritivo, o descritivo e o produtivo. Tais tipos não são excludentes e devem estar bem esclarecidos para o professor, uma vez que ele os utilizará de acordo com seus objetivos em momentos específicos.

O ensino prescritivo, para o autor, "objetiva levar o aluno a substituir seus próprios padrões de atividade linguística considerados errados/inaceitáveis por outros considerados corretos/aceitáveis" (TRAVAGLIA, 2009, p. 38). Desse modo, esse tipo de ensino está diretamente ligado à gramática normativa, privilegiando somente a norma culta da língua e preocupando-se penas com a correção formal da linguagem.

Já o ensino descritivo "objetiva mostrar como a linguagem funciona e como determinada língua em particular funciona" (TRAVAGLIA, 2009, p. 39). Nesse caso, o ensino não se volta apenas para a norma culta da língua, mas sim para todas as variedades linguísticas.

O ensino produtivo, por sua vez, "objetiva ensinar novas habilidades linguísticas. Quer ajudar o aluno a estender o uso de sua língua materna de maneira mais eficiente" (TRAVAGLIA, 2009, p. 39). Assim, o aluno teria a sua disposição um número elevado de potencialidades da língua nas mais diversas situações, desenvolvendo sua competência comunicativa.

Com base nisso, podemos perceber que a evolução das concepções de gramática e de ensino está estritamente relacionada com o avanço das descobertas científicas e com as necessidades de cada época. Em razão disso, acreditamos estar em um momento no qual o 
ensino de gramática deva ser repensado, pois as escolas não podem mais ensinar gramática tradicional pura em pleno século XXI. Mendonça (2006) levanta esta questão ao afirmar que

a escola não tem de formar gramáticos ou linguistas descritivistas, e sim pessoas capazes de agir verbalmente de modo autônomo, seguro e eficaz, tendo em vista os propósitos das múltiplas situações de interação em que estejam engajadas. (MENDONÇA, 2006, p. 204)

Essa mudança no ensino de gramática, porém, não significa que ela deva ser deixada de lado, até porque não há como fazer isso, sendo que ela está constantemente presente em nosso dia-a-dia. O que defendemos é o estudo de uma gramática contextualizada (que se aproxima da cognitivo-funcional), da qual possa emergir uma prática de análise lingúística. Bezerra e Reinaldo (2013) sinalizam que a expressão análise linguística surgiu associada ao ensino de Língua Portuguesa na década de 80 e, no final da década de 90, foi incorporada como eixo de ensino nos documentos oficiais.

De acordo com Neves (2006), essa gramática contextualizada deve propiciar e conduzir a reflexões sobre o funcionamento da linguagem:

A natureza da gramática que se defende para uso escolar é, pois, a de uma gramática não desvinculada dos processos de constituição do enunciado, ou seja, dirigida pela observação da produção linguística efetivamente operada. (NEVES, 2006, p.22)

Para Mendonça (2006), a análise linguística constitui, ao lado da leitura e da produção de textos, um dos três eixos básicos para o ensino de língua materna. Essa importância provém de uma de suas características, a reflexão recorrente e organizada, que é voltada para a produção de sentidos e tem a finalidade de formar leitores/escritores dos mais variados gêneros textuais.

Ao contrário do que é entendido por muitos professores, a análise linguística não elimina a gramática das aulas, mas realiza uma abordagem a partir de um paradigma diferente. A figura a seguir exemplifica essa diferença:

Tabela 1: Diferenças básicas entre ensino de gramática normativa e análise linguística.

\section{ENSINO DE GRAMÁTICA}

Concepção de língua como sistema, estrutura inflexível e invariável.

Fragmentação entre os eixos de ensino: as aulas de gramática não se relacionam necessariamente com as de leitura e de produção textual.

Metodologia transmissiva, baseada na exposição dedutiva (do geral para o particular, isto é, das regras para o exemplo) + treinamento.

\section{PRÁTICA DE ANÁLISE LINGUÍSTICA}

Concepção de língua como ação interlocutiva situada, sujeita às interferências dos falantes.

Integração entre os eixos de ensino: a análise linguística é ferramenta para a leitura e a produção de textos.

Metodologia reflexiva, baseada na indução (observação dos casos particulares para a conclusão das regularidades/regras). 


\begin{tabular}{|c|c|}
\hline Privilégio das habilidades metalinguísticas. & $\begin{array}{l}\text { Trabalho paralelo com } \\
\text { metalinguísticas e epilinguísticas. }\end{array}$ \\
\hline $\begin{array}{l}\text { Enfase nos conteúdos gramaticais como objetos de } \\
\text { ensino, abordados isoladamente e em sequência } \\
\text { mais ou menos fixa. }\end{array}$ & $\begin{array}{l}\text { Enfase nos usos como objetos de ensino } \\
\text { (habilidades de leitura e escrita), que remetem a } \\
\text { vários outros objetos e ensino (estruturais, textuais, } \\
\text { discursivos, normativos), apresentados e } \\
\text { retomados sempre que necessário. }\end{array}$ \\
\hline Centralidade da norma padrão. & Centralidade dos efeitos de sentido. \\
\hline $\begin{array}{l}\text { Ausência de relação com as especificidades dos } \\
\text { gêneros, uma vez que a análise é mais de cunho } \\
\text { estrutural e, quando normativa, desconsidera o } \\
\text { funcionamento desses gêneros nos contextos de } \\
\text { interação verbal. }\end{array}$ & $\begin{array}{l}\text { Fusão com o trabalho com os gêneros, na medida } \\
\text { em que contempla justamente a intersecção das } \\
\text { condições de produção dos textos e as escolhas } \\
\text { linguísticas. }\end{array}$ \\
\hline $\begin{array}{l}\text { Unidades privilegiadas: a palavra, a frase e o } \\
\text { período. }\end{array}$ & Unidades privilegiadas: o texto. \\
\hline $\begin{array}{l}\text { Preferência pelos exercícios estruturais, de } \\
\text { identificação e classificação de unidades/funções } \\
\text { morfossintáticas e correção. }\end{array}$ & $\begin{array}{l}\text { Preferência por questões abertas e atividades de } \\
\text { pesquisa, que exigem comparação e reflexão sobre } \\
\text { adequação e efeitos de sentido. }\end{array}$ \\
\hline
\end{tabular}

Fonte: Mendonça (2006, p. 207)

Podemos perceber que a principal diferença entre o ensino de gramática normativa e a análise linguística se sustenta na substituição da classificação e da identificação pela reflexão. Desse modo, ao analisar alguns dos pontos da proposta de análise linguística citados acima como tomar como unidade privilegiada o texto, centrarr-se na produção de efeitos de sentido e conceber língua como uma ação interlocutiva situada - fica evidente que ela se constitui como uma ferramenta para potencializar as habilidades do sujeito no seu dia-a-dia, principalmente sua competência discursiva em variadas situações, como já ressaltam os PCN de Língua Portuguesa.

Mas e os livros didáticos, será que englobam a prática de análise linguística? Qual perspectiva de gramática é enfocada nos livros didáticos? Essas são algumas das questões norteadoras deste trabalho. Mas, antes disso, precisamos entender a trajetória do livro didático até os dias atuais, tópico que será desenvolvido na seção seguinte.

\section{Histórico do livro didático no ensino fundamental}

Atualmente, o livro didático (doravante LD) compartilha espaço no universo escolar com diversos instrumentos e materiais didáticos, sejam eles tradicionais ou mais atuais. Mesmo assim, ele mantém seu papel central na sala de aula e é considerado um dos principais aliados do professor no processo de ensino-aprendizagem.

Para que o LD chegasse ao ensino fundamental das escolas brasileiras da forma como o conhecemos hoje, passou por vários processos de (re)elaboração ao longo das décadas. Para 
Freitag, Costa e Motta (1989, p.11 apud Dominguini, 2010, p. 8-9) a história do livro didático no Brasil

não passa de uma sequência de decretos, leis e medidas governamentais que se sucedem, a partir de 1930, de forma aparentemente desordenada, e sem a correção ou a crítica de outros setores da sociedade.

Segundo Freitas e Rodrigues (2007), a trajetória do LD até as escolas teve maior crescimento em 1929, com a criação do Instituto Nacional do Livro (INL). A partir de então, muitos foram os avanços e conquistas para a consolidação do atual programa de distribuição de obras didáticas para estudantes da rede pública de ensino no país, o Programa Nacional do Livro Didático (PNLD). Alguns dos avanços mais significativos ocorreram entre os anos 30 e 90 do século XX.

Em 1938 é instituída a Comissão Nacional do Livro Didático (CNLD), a primeira política de legislação e controle de produção e de circulação do liyro didático no país que, de acordo com Santos (2007, p.27), foi "instituída com o objetivo de controle político e ideológico mais do que com objetivos didáticos". Sete anos mais tarde, em 1945, essa legislação é consolidada, proporcionando aos professores uma aparente liberdade de escolherem os livros com os quais queriam trabalhar. Esta liberdade antes não existia, pois "cabia a outro (o governo) avaliar o que seria estudado e como seria ensinado, ficando com o professor a responsabilidade de passar os conteúdos às crianças". (BATISTA, 2011, p .20)

O ano de 1985 é mareado pelo surgimento do atual Programa Nacional do Livro Didático (PNLD), em substituição ao Programa do Livro Didático-Ensino Fundamental (PLIDEF). O PNLD instituiu alterações significativas para o ensino, tais como a reutilização do livro em anos posteriores (fim do livro descartável), e, embora tenha sido criado em 1985, institui o processo de avaliação prévia somente em 1996. Neste ano, o PNLD "teve as suas características modificadas, passando a ter como principais objetivos avaliar, adquirir e distribuir de forma universal e gratuita os LD para todo o Ensino Fundamental público.” (SANTOS, 2007, p. 31). Desse modo, no mesmo ano, é publicado o primeiro "Guia de Livros Didáticos".

Exposto nosso referencial teórico, apresentamos, na seção seguinte, nossa metodologia - que engloba o universo de pesquisa, o corpus e os procedimentos de análise adotados - e os resultados a que chegamos com essa pesquisa. 


\section{Metodologia}

\subsection{Universo de pesquisa}

O universo de pesquisa deste trabalho é o livro do $6^{\circ}$ ano pertencente à coleção Português: linguagens (CEREJA; MAGALHÃES, 2012). Selecionamos esta coleção porque foi escolhida, conjuntamente, pelas escolas municipais e estaduais de Cerro Largo (RS), município no qual atuamos/pesquisamos. Neste trabalho, entretanto, optamos por considerar apenas as quatro escolas estaduais do município.

\subsection{Corpus}

O livro em análise é constituído de quatro unidades com temas variados, sendo que cada uma é composta por três capítulos e, em seguida, há a presença de um capítulo especial, intitulado "Intervalo", que propõe o desenvolvimento de um projeto relacionado ao tema da unidade. Esses capítulos (com exceção do "intervalo") estão organizados em cinco seções²: estudo do texto; produção de texto; para escrever com adequação/coerência/coesão/expressividade, a língua em foco; de olho na escrita.

Dentre elas, selecionamos para análise a língua em foco, que aborda os aspectos gramaticais da língua. Esta seção é subdividida nos seguintes tópicos: construindo o conceito; conceituando; a categoria gramatical estudada na construção do texto; semântica e discurso.

Apesar de a seção aparecer nos capítulos de todas as unidades, optamos por desconsiderar, neste momento, a unidade 1, pois ela não enfoca a gramática propriamente dita, que é o aspecto sobre o qual nos debruçamos.

O quadro a seguir traz uma visão geral das unidades 2,3 e 4 do volume do $6^{\circ}$ ano, enfatizando o tema da seção língua em foco em cada capítulo:

\begin{tabular}{|c|c|c|c|}
\hline UNIDADE & CAPÍTULO & $\begin{array}{l}\text { TEMA DA SEÇÃO LÍNGUA } \\
\text { EM FOCO }\end{array}$ & $\begin{array}{l}\text { PÁGINAS } \\
\text { DA SEÇÃO }\end{array}$ \\
\hline \multirow{3}{*}{$\begin{array}{c}2 \\
\text { Crianças }\end{array}$} & 1 - Coisa de criança & Substantivo & $85-93$ \\
\hline & 2 - Uma questão de valor & Adjetivo & $106-111$ \\
\hline & 3 - Hora de diversão! & $\begin{array}{l}\text { Flexão dos substantivos e } \\
\text { adjetivos: gênero e número }\end{array}$ & $118-124$ \\
\hline
\end{tabular}

\footnotetext{
${ }^{2}$ Nem todos os capítulos possuem as cinco seções; em alguns casos, determinadas seções não aparecem, como é o caso da seção Estudo do texto, por exemplo.
} 


\begin{tabular}{|c|c|c|c|}
\hline \multirow{3}{*}{$\begin{array}{c}3 \\
\text { Descobrindo } \\
\text { quem sou eu }\end{array}$} & $1-O$ encantador de melros & $\begin{array}{l}\text { Flexão dos substantivos e } \\
\text { adjetivos: grau }\end{array}$ & $139-147$ \\
\hline & 2 - Eu: o melhor de mim & Artigo & $158-163$ \\
\hline & 3 -Em busca do sonho & Numeral & $176-181$ \\
\hline \multirow{3}{*}{$\begin{array}{c}4 \\
\begin{array}{c}\text { Verde, adoro } \\
\text { ver-te }\end{array}\end{array}$} & $\begin{array}{l}1-\text { Natureza morta ou } \\
\text { natureza-morta? }\end{array}$ & Pronome & $193-206$ \\
\hline & 2 - A natureza em pânico & Verbo (I) & $222-232$ \\
\hline & $3-$ S.O.S animal & Verbo (II) & $246-252$ \\
\hline
\end{tabular}

\subsection{Procedimentos de análise}

Nossos procedimentos de análise subdividem-se em dois momentos. Inicialmente, realizamos uma análise contextual, com a qual objetivamos compreender como a coleção, de modo geral, é descrita e avaliada tanto por seus autores quanto por leitores externos, comparando essas percepções. Para isso, investigamos o manual do professor contido no final do livro do $6^{\circ}$ ano, o Guia de livros didáticos de Língua Portuguesa para os anos finais do Ensino Fundamental e questionários respondidos pelo professor de Língua Portuguesa de três escolas estaduais do município ${ }^{3}$. Esses questionários visam identificar por que os professores adotaram a coleção e como esta foi avaliada por eles.

Em um segundo momento, realizamos uma análise textual, na qual analisamos as unidades constituintes do livro com base nas diferenças propostas por Mendonça (2006) entre ensino de gramática normativa e análise linguística. Com isso, pretendemos identificar a perspectiva de ensino de gramática recorrente na coleção (em específico no livro do $6^{\circ}$ ano).

Na seção seguinte, apresentamos nossas análises (textual e contextual), bem como os resultados a que chegamos com nossa pesquisa.

\section{Análise e discussão}

\subsection{Análise contextual}

A coleção Português: linguagens (2012), de autoria de William Roberto Cereja e Thereza Anália Cochar Magalhães, está em sua $7^{\mathrm{a}}$ edição. Revista, ampliada e atualizada, esta nova edição promete alargar o horizonte das atividades que envolvem leitura, produção de textos e reflexão sobre a linguagem. Para alcançar este objetivo, os autores defendem, no manual do professor, a adoção de medidas básicas que possam renovar o ensino de língua

\footnotetext{
${ }^{3}$ Embora o município tenha quatro escolas estaduais, o professor de uma delas não retornou o questionário.
} 
portuguesa: inclusão de novos conteúdos; mudança de postura em relação à língua (inserindo a noção de adequação/inadequação no lugar de certo/errado e discutindo questões de variedades linguísticas, por exemplo); inserção de situações concretas de interação discursiva, entre outras.

Tal coleção possui volumes do $6^{\circ}$ ao $9^{\circ}$ ano do Ensino Fundamental e foi aprovada no processo avaliatório do PNLD/2014, estando presente, desse modo, no Guia de livros didáticos de Língua Portuguesa para os anos finais do Ensino Fundamental.

Este guia está disponível online e apresenta aos professores das escolas públicas as coleções didáticas de Língua Portuguesa aprovadas e suscetíveis de escolha para utilização nas escolas entre os anos de 2014 e 2016. Tais coleções são apresentadas em forma de resenha, dando uma visão geral destas ao levantar pontos fortes e fracos.

Português: linguagens é apresentada no Guia como uma coleção do tipo 2, ou seja, valese de um DVD (por volume) que contém atividades digitais complementares. Sua análise parte de quatro eixos: leitura, produção de texto, oralidade e conhecimentos linguísticos. A abordagem do texto literário é considerada o ponto fraco da coleção e, em contrapartida, o ponto forte são as atividades de leitura, como percebemos abaixo:

As propostas diversificadas de leitura, o trabalho com a produção de gêneros textuais, orais e escritos e as atividades que buscam o ensino reflexivo da língua são aspectos positivos da coleção que podem ser potencializados em sala de aula. (BRASIL, 2013, p.89, grifo nosso)

Em relação aos conteúdos gramaticais, o Guia apresenta uma vaga explicação, não deixando claro para o professor em que perspectiva serão desenvolvidos nem como devem ou podem ser didatizados. Ele afírma que a maioria das atividades é configurada como jogo pouco se distinguindo das que são encontradas em outros materiais didáticos-, sem especificar qual o entendimento ou concepção de jogo. Porém, é salientado que seu valor vai além do lúdico, pois estas atividades oferecem ao aluno a resposta pretendida e, em alguns casos, explicam as regras que justificam a resposta.

Quanto ao eixo dos conhecimentos linguísticos, o Guia ressalta que o trabalho abrange conteúdos da tradição gramatical juntamente com conhecimentos textuais e discursivos. Desse modo, há uma mescla de momentos transmissivos e reflexivos, pois as atividades exigem tanto identificação e classificação de formas e construções sintáticas quanto análise de efeitos de sentido em decorrência do emprego de recursos linguísticos.

Estas percepções do Guia se assemelham muito às dos professores de língua portuguesa que responderam ao questionário proposto (anexo 1), embora dois dos três professores afirmem 
que o Guia não lhes foi apresentado. Os professores ressaltam, de modo geral, a presença de atividades diferenciadas - principalmente em relação aos textos (multimodais) - e de conhecimentos/aspectos linguísticos, apesar de um professor afirmar que o livro é pobre quanto à análise da situação sócio-comunicativa na qual os textos estão inseridos.

Em relação à percepção da gramática na coleção, as respostas são distintas, pois enquanto dois professores ressaltam a relação entre gramática e texto - inclusive tratando de gramática contextualizada -, outro salienta que a gramática está, em sua grande maioria, na perspectiva "bem tradicional".

Outro ponto que chama atenção nos questionários é que um professor afirma ter escolhido, através do Guia de livros didáticos, outra coleção para sua escola. Porém, como todas as escolas do município queriam unificar o livro, a coleção Português: linguagens foi adotada por todas.

Além disso, outra questão relevante do questionário foi em relação à avaliação da coleção e de seus pontos fortes. Nela, os professores reiteram a presença dos textos, dando ênfase às análises relacionadas aos aspectos linguísticos e semióticos.

Diante de todas essas percepções/avaliações da coleção, analisamos, a seguir, as unidades do livro do $6^{\circ}$ ano a fim de identificar qual concepção de gramática está presente nele. Além disso, buscamos investigar em que medida as descrições sobre a coleção realmente se efetivam no livro.

\subsection{Análise textual}

Nossa análise textual, conforme mencionado anteriormente, parte das diferenças apontadas por Mendonça (2006) entre o ensino gramatical normativo e a análise linguística. A autora aponta nove categorias que podem evidenciar essa diferenciação (ver figura 1): concepção de língua; organização dos eixos de ensino; metodologia; habilidades privilegiadas; objeto de ensino; centralidade do ensino; trabalho com gêneros; unidades privilegiadas e composição dos exercícios. Destas, selecionamos, para este trabalho, três que podem ser entendidas como tópicos centrais para realizar a diferenciação: concepção de língua, organização dos eixos de ensino e metodologia.

Nesse sentido, temos três macro-categorias que englobam as demais. Da categoria concepção de língua entendemos que fazem parte as habilidades, unidades privilegiadas, objeto e centralidade do ensino. Já a categoria organização dos eixos de ensino abarca a composição 
dos exercícios, enquanto que a metodologia agrega o trabalho com gêneros. O quadro a seguir sistematiza as categorias:

Quadro 2: Macro e micro categorias propostas.

\begin{tabular}{|c|c|}
\hline Macro-categorias & Micro-categorias \\
\hline \multirow{2}{*}{ Concepção de língua } & Habilidades \\
\cline { 2 - 2 } & Unidades privilegiadas \\
\cline { 2 - 2 } & Objeto de ensino \\
\cline { 2 - 2 } & Centralidade do ensino. \\
\hline Organização dos eixos de ensino & Composição dos exercícios \\
\hline Metodologia & Trabalho com gêneros \\
\hline
\end{tabular}

A concepção de língua, segundo Mendonça (2006), pode ser entendida como sistema e estrutura invariável, no estudo de gramática tradicional, ou como ação interlocutiva situada, no caso da análise linguística. No livro analisado, percebemos que, em alguns momentos, é explorado o uso coloquial e popular da língua - principalmente ao abordar artigos e pronomes de tratamento -, o que poderia se aproximar de uma análise linguística, como mostra o exemplo 1:

Exemplo1: Atualmente, alguns especialistas defendem a inclusão de você, vocês e da expressão a gente entre os pronomes pessoais, pelo fato de essas, cada dia mais, estarem sendo utilizadas, respectivamente, em lugar e tu, vós e nós. (p. 196)

Contudo, o que prevalece é a noção de língua como estrutura invariável, sem grandes espaços para as variedades linguísticas e para a adequação da linguagem a diferentes contextos. A análise das habilidades e unidades privilegiadas sustenta essa afirmação, pois o aluno é levado a identificar e classificar classes de palavras, utilizando o texto como pretexto para localizá-las. Desse modo, as unidades privilegiadas são período, frase e, principalmente, palavra, como mostram os exemplos a seguir:

Exemplo 2: No $1^{\mathrm{o}}$ quadrinho, a personagem utiliza quatro pronomes. Quais são eles? Como se classificam? (p. 201)

Exemplo 3: Na tira, a personagem aponta algumas características do filme a que assistiu. Destaque os adjetivos que ela empregou para caracterizar [...]. (p. 107)

Exemplo 4: Reconheça e classifique o artigo empregado no poema. (p. 160)

Exemplo 5: Na locução adjetiva com leves reflexos acobreados, que adjetivos caracterizam o substantivo reflexos? (p. 110) 
O aluno é levado também a ler definição de conceitos. Nesse caso, percebemos que há uma tentativa de tratar da análise linguística ao desenvolver a subseção "Construindo o conceito". Porém, nessa suposta construção, não há espaço para o aluno elaborar por conta própria (indução) um conceito a partir do exposto anteriormente, ou seja, ele não participa ativamente desse processo.

Além disso, entendemos que prevalece a concepção de língua como estrutura invariável levando em consideração o objeto e a centralidade do ensino presentes no livro didático. Quanto ao objeto de ensino, identificamos que este, às vezes, reflete sobre o uso dos conteúdos gramaticais e sobre seu efeito de sentido, principalmente nas subseções "Semântica e discurso" e "Na construção do texto". Os exemplos 6, 7 e 8 mostram essa reflexão:

Exemplo 6: O humor da tira surge com a quebra de expectativa do leitor. Explique como se dá essa quebra. (p. 90)

Exemplo 7: No $1^{\circ}$ balão, Tita diz: "Olha! Vou querer ele curto!" A palavra ele se refere a um substantivo que não foi mencionado na tira. Com base no contexto, responda: Qual é esse substantivo? (p. 110)

Exemplo 8: Há, na língua portuguesa, muitos substantivos que trazem sufixos formadores de aumentativos e diminutivos, mas perderam ao longo do tempo esses valores e adquiriram significados especiais. (p. 141)

Porém, a ênfase é dada aos conteúdos gramaticais, sendo que, mais uma vez, predomina a exposição de frases (normalmente retiradas de tiras e de fragmentos de textos) com a finalidade de o aluno identificar classes de palavras. Desse modo, fica explícito que a centralidade do ensino está na norma padrão, uma vez que a maioria das explicações, definições e atividades foca quase que exclusivamente a norma padrão da língua, raramente tratando de temas como a variação linguística, por exemplo. Salientamos que o tema variação linguística foi abordado na coleção como um tópico a parte, estando presente mais fortemente no início do livro didático.

Os exemplos a seguir evidenciam como o objeto e a centralidade do ensino colaboram para a construção de uma concepção de língua como invariável:

Exemplo 9: Substantivos são palavras que nomeiam seres - visíveis ou não, animados ou não -, ações, estados, sentimento, desejos e ideias. (p. 86)

Exemplo 10: Nas frases a seguir, alguns pronomes estão empregados em desacordo com a norma-padrão. Reescreva as frases, empregando tais pronomes de acordo com essa variedade. (p. 205) 
Exemplo 11: Além de ações, os verbos também designam estado, mudança de estado e fenômenos meteorológicos. (p. 223)

Exemplo 12: Um substantivo pode ter várias classificações. Observe: pescoço: substantivo primitivo, simples, comum e concreto. (p. 89)

Com tudo isso, pretendemos evidenciar que a concepção de língua adotada pelo livro didático segue uma postura do ensino tradicional da gramática, embora, algumas vezes, estejam presentes questões que remetam a uma busca por uma prática de análise linguística.

Em relação aos eixos de ensino, Mendonça (2006) aponta que, na gramática tradícional, são fragmentados, ou seja, as aulas de gramática não se relacionam às de leitura e de produção textual. Já no caso da análise linguística, os eixos estão integrados, sendo que ela é ferramenta para a leitura e a produção de textos.

Com base nessa explicação, consideramos que o livro didático em questão adota um comportamento, mais uma vez, tradicional. Isso ocorre porque os eixos de ensino estão fragmentados, como se estivessem em "gavetas" diferentes. Exemplo dessas "gavetas" ocorre ao tratar de uma classe de palavras em subseções isoladas - construção do conceito, conceituação, classe gramatical na construção do texto e sua relação na semântica e no discurso -, como se um conceito não pudesse ser trabalhado partindo de um texto e da relação de sentido estabelecida nele.

Levando em consideração olivro didático em sua totalidade, essa fragmentação também ocorre, pois a gramática aparece isolada da produção textual e do texto que inicia a unidade, sendo que a gramática é o último ponto a ser desenvolvido em cada capítulo.

Essa separação se reflete na composição dos exercícios, nos quais é dada preferência à estrutura (identifícação e classificação de unidades e de funções morfossintáticas) em lugar da reflexão a respeito do uso da linguagem, que ocorre ocasionalmente. Assim, poucas vezes o aluno ganha voz para expor sua interpretação, pois só há uma forma "correta", que deve estar de acordo com norma padrão. Além disso, o uso do imperativo também evidencia a presença de exercícios estruturais.

Os exemplos a seguir, em consonância com os apresentados anteriormente (de 2 a 5), ilustram porque os exercícios são considerados estruturais:

Exemplo 13: A palavra Diário foi empregada como substantivo próprio. Que outro substantivo próprio há no texto? (p. 89)

Exemplo 14: Que tipos de numerais foram empregados no texto? (p. 181) 
Exemplo 15: Identifique e classifique os pronomes deste texto. (p. 204)

Exemplo 16: Reconheça o modo em que estão as formas verbais destacadas no texto. (p. 227)

Já a metodologia, que para Mendonça (2006) é caracteriza como transmissiva no ensino de gramática e como reflexiva na prática de análise linguística, novamente se apoia na gramática tradicional no livro analisado. Isso é constatado pela forte presença de explicações e atividades que partem do geral para o particular, isto é, das regras para o exemplo, sendo seguidas, muitas vezes, de certo treinamento. Os exemplos a seguir comprovam essa afirmação:

Exemplo 17: Adjetivos compostos - São os adjetivos formados por duas ou mais palavras: camiseta azul-marinho; política econômico-financeira. (p. 108)

Exemplo 18: O feminino dos substantivos geralmente é formado pela troca de -o por -a ou pelo acréscimo da vogal -a no final da palavra, Veja: rato - rata; leitor leitora. (p. 120)

Exemplo 19: Artigos definidos - São os artigos o(s) e a(s), que definem os substantivos indicando que se trata de seres já conhecidos. Exemplos: o anúncio, a pergunta, as revistas, os endereços. (p. 159)

Exemplo 20: Os numerais um e dois e os que indicam centenas, a partir de duzentos, apresentam também forma feminina. Os demais cardinais são invariáveis. Veja: um jornal - uma revista; dois meninos - duas meninas; duzentos livros - duzentas fichas; cinco lençóis - cinco fronhas. (p. 178)

Uma exceção pode de novo ser considerada a subseção "Construindo o conceito", na qual, como já exposto antes, há uma tentativa de realizar um processo de conclusão/generalização de regras. O exemplo 21 ilustra esta situação:

Exemplo 21: No $1^{\circ}$ quadrinho, a pessoa que fala com Overman diz: "Anote o endereço". Na sua opinião, por que ela empregou o e não um? (p. 158)

Essa tentativa ocorre por meio de interpretação de tiras, fotos, poemas, histórias em quadrinhos e fábulas. Contudo, embora esses gêneros textuais estejam presentes no livro, na seção "língua em foco" são utilizados somente como pretexto, para que deles possam ser retiradas frases e classificadas palavras (como já ficou explícito nos exemplos anteriores). Desse modo, não há análises quanto às características estruturais e sociocomunicativas destes 
gêneros, o que reforça a ideia de uma fragmentação dos eixos de ensino e de um ensino tradicional de gramática.

\section{Considerações finais}

Levando em consideração as concepções de ensino e de gramática apresentadas por Martelotta (2009) e por Travaglia (2009) e comparando-as com as análises realizadas anteriormente, podemos afirmar que o livro do $6^{\circ}$ ano baseia-se, em grande parte, em um ensino prescritivo, concebendo a língua de forma tradicional e estrutural. Em razão disso, muitas das afirmações feitas no Guia do Livro Didático e no Manual do Professor a respeito da coleção Português: linguagens não se efetivam, criando certa incompatibilidade entre o que foi pretendido e o que realmente foi elaborado.

Com tudo isso, enfatizamos a necessidade de repensar o ensino de gramática nas escolas. Entendemos que este ensino deva se apropriar de práticas de análise linguística, nas quais sejam destacados os efeitos de sentido dos textos, sejam eles orais ou escritos. Afinal, a língua enquanto ação interlocutiva situada - está a todo momento sofrendo intervenções e modificações de seus falantes e, desse modo, não pode permanecer estática no tempo.

\section{Referências bibliográficas}

BATISTA, A. P. Uma análise da relação professor e o livro didático. Monografia de Graduação em Pedagogia. Salvador: Universidade do Estado da Bahia, 2011.

BEZERRA, M. A.; REINALDO, M. A. Análise linguística: afinal, a que se refere? São Paulo, Cortez, 2013.

BRASIL. Ministério da Educação. Guia de livros didáticos - PNLD 2014: língua portuguesa - ensino fundamental - anos finais. Brasília, 2013.

CEREJA, W. R.; MAGalhães, T. C. Português: linguagens. $6^{\circ}$ ano. 7. ed. reform. São Paulo: Saraiva, 2012.

DOMINGUINI, L. Fatores que evidenciam a necessidade de debates sobre o livro didático. In: V CINFE - Congresso Internacional de Filosofia e Educação, Caxias do Sul, maio 2010. Disponível em: $<$ http://www.ucs.br/ucs/tplcinfe/eventos/cinfe/artigos/artigos/arquivos/eixo tematico 7/Fatores $\% 20$ que $\% 20$ Evidenciam $\% 20 \mathrm{a} \% 20$ Necessidade $\% 20 \mathrm{de} \% 20$ Debates $\% 20$ sobre $\% 20 \mathrm{o} \% 20$ Livro \%20Didatico.pdf >. Acesso em: 21 nov. 2013.

FREITAS, N. K.; RODRIGUES, M. H. O livro didático ao longo do tempo: a forma do conteúdo. DAPesquisa, Florianópolis, n.3, v. 1, ago. 2007. Disponível em: 
$<$ http://www.ceart.udesc.br/revista dapesquisa/volume3/numero1/visuais.htm $>$. Acesso em: 19 set. 2013.

MARTElOtTA, M. E. (org.). Manual de linguística. São Paulo: Contexto, 2009.

MENDONÇA, M. Análise linguística no ensino médio: um novo olhar, um outro objeto. In: BUNZEN, C.; MENDONÇA, M. (org.). Português no ensino médio e formação do professor. São Paulo: Parábola Editorial, 2006.

NEVES, M. H. M. Que gramática estudar na escola? 3.ed. São Paulo: Contexto, 2006.

ROJO, R. Gêneros de discurso/texto como objeto de ensino de línguas: um retorno ao trivium? In: SIGNORINI, I. (org.) [Re] Discutir texto, gênero e discurso. São Paulo: Parábola, 2008.

SANTOS, C. M. C. O livro didático do ensino fundamental: as escolhas do professor. Dissertação de Mestrado. Curitiba: Universidade Federal do Paraná, 2007.

SOARES, M. Português na escola: história de uma disciplina curricular. In: BAGNO, M. (org.). Linguística da norma. 2. ed. São Paulo: Edições Loyola, 2004.

TRAVAGLIA, L. C. Gramática e interação: uma proposta para o ensino de gramática. 13. ed. São Paulo: Cortez, 2009.

\section{ANEXO 1}

\section{Questionário com professores de Língua Portuguesa}

Prezado(a) professor(a),

Estamos realizando uma pesquisa, vinculada ao Programa Institucional de Bolsas de Iniciação Científica (PROBIC/FAPERGS) da Universidade Federal da Fronteira Sul, sobre a adoção, pelas escolas estaduais do município, da coleção Português: linguagens, que será utilizada entre os anos 2014 e 2016.

\section{Perfil do(a) Professor(a)}

Desde já, agradecemos sua colaboração.

1. Qual sua área de formação (curso em nível superior e ano de conclusão)?

P1: Licenciatura Plena em Letras - concluída em 1996.

$\underline{P 2:}$ Letras - Lingua Portuguesa e Inglesa com as respectivas literaturas. Ano de conclusão = 1998 .

P3: Licenciatura em Letras (curta - 1998; plena - 2001).

2. Possui pós-graduação? Se sim, qual o ano de conclusão?

P1: Sim. Especialização em Ensino-Aprendizagem de Línguas - Inglês; concluída em 2003.

P2: Sim, ano 2005.

P3: Sim, 2003.

3. Há quantos anos você trabalha em educação?

P1: Há vinte anos. 
P2: 18 anos.

P3: Há 30 anos.

\section{Qual seu tempo de docência?}

P1: Vinte anos.

P2: 8 anos.

P3: 30 anos.

5. Em qual(is) escola(s) você atua?

P1: Escola Estadual de Educação Básica Eugênio Frantz e Escola Municipal de Ensino Fundamental Don Pedro II.

P2: Escola Estadual de Ensino Fundamental Sargento Sílvio Delmar Hollenbac e Colégio Estadual Athayde Pacheco Martins.

P3: Escola Estadual de Ensino Fundamental Padre Traezel.

6. Em quais séries e/ou anos você leciona?

P1: $6^{\circ}$ e $7^{\circ}$ anos e $8^{a}$ série.

P2: Séries Finais e Ensino Médio.

P3: Nas $6^{a}$ séries A e B (9 anos) e na $7^{a}$ (8 anos).

7. Que disciplinas vocês ministra nas escolas anteriormente citadas?

$\underline{P 1}$ : Língua Portuguesa, Língua Inglesa e Língua Alemã.

P2: Lingua Portuguesa e Lingua Inglesa.

P3: Lingua Portuguesa.

8. Qual sua carga horária semanal (e número de horas em sala de aula)?

P1: Estado - 20h semanais; Município -22 h semanais +11 h (convocação temporária).

P2: 40h/29h em sala.

P3: Carga horária de 20h e em sala, 15.

2. Aspectos relacionados à adoção da coleção Português: linguagens

\section{Como você utiliza o livro didático em sua aula?}

P1: procuro utilizar os textos dos livros sempre que contemplam os gêneros a serem trabalhados na sérielano e também para atividades relacionadas aos conteúdos de forma contextualizada.

P2: Como um instrumento de orientação e complementação didático-pedagógica.

P3: Mesmo sendo só um material de apoio pedagógico, utilizo na maioria das aulas, mas complementando com outro material.

\section{Que critérios foram mais relevantes na escolha da coleção adotada?}

P1: Selecionamos o livro por oferecer atividades diferenciadas em que os aspectos gramaticais são trabalhados, também, a partir dos textos na seção "Semântica do Discurso".

P2: Os gêneros abordados, as atividades de compreensão e interpretação de texto e os conhecimentos linguísticos apresentados. 
P3: Pelo que me informaram, pela análise dos eixos: de leitura (textos multimodais); produção textual; da oralidade e dos conhecimentos linguísticos. Também por vir acompanhado de CD.

3. Como você percebeu a presença da gramática (análise linguística) na coleção?

P1: Em cada capitulo, os autores procuram contextualizar a gramática, dando ênfase à mesma na construção do texto.

P2: A coleção compreende conteúdos gramaticais partindo de um texto que é explorado, complementando com exercícios de aplicação.

P3: É explorada, em parte, a partir do texto/contexto, mas a maior parte da gramática está na perspectiva bem tradicional.

4. Os autores da coleção afirmam que nela "O estudo da gramática é inovador: toma o texto como objeto de ensino, abordando-o a partir das mais recentes contribuições da Linguística e da Teoria do Discurso." Você concorda? Por quê?

P1: De fato, são poucos os autores que procuram fazê-lo dessa forma, porém, percebo que o livro ainda é pobre quanto à análise da situação sócio-comunicativa em que os textos são produzidos (público-alvo, contexto e meios de produção e circulação...).

P2: Sim, a gramática está unida ao conhecimento textual e discursivo.

P3: Já respondi na questão anterior.

5. O Guia de Livros Didáticos (PNLD 2014), elaborado pelo MEC e disponível on-line, traz uma resenha das coleções disponíveis para escolha. Você conhece esse guia? Ele teve influência na sua decisão?

P1: Não. A escolha deu-se pela análise dos exemplares recebidos das editoras.

P2: Não nos foi apresentado.

P3: Eu e o prof. X lemos todas as resenhas do Guia. Tínhamos escolhido "Universos - Língua Portuguesa", mas como as escolas querem unificar o livro...

6. Houve consenso entre os professores de língua portuguesa da sua escola na escolha da coleção? Alguma outra coleção foi cogitada? Se sim, qual?

P1: Não. Uma representante de escola (prof. ${ }^{a}$ ) optava por outra coleção (não lembro o nome), no entanto, aderiu à escolha do grande grupo.

P2: Sim, houve consenso entre os professores.

P3: Já respondi.

7. De forma geral, como você avalia a coleção? Quais são seus pontos fortes?

P1: Gostei da exploração dos aspectos linguísticos feita a partir do texto, pois, infelizmente, durante a minha formação não fui preparada para trabalhar dessa forma.

P2: Das coleções avaliadas esta é a que melhor se aplica. Trabalha a textualidade de maneira clara e precisa utilizando-se de diversos recursos semióticos.

P3: Destaque para análise de textos visuais e de textos compostos de linguagem verbal e imagens; propostas de projetos. Contribuição teórico-metodológica para o uso da coleção (subsidios para o professor).

Artigo recebido em: 25.02.2014

Artigo aprovado em: 29.04.2014 